\title{
OPEN Threshold voltage instability and polyimide charging effects of LTPS TFTs for flexible displays
}

\author{
Hyojung Kim ${ }^{1,2}$, Jongwoo Park ${ }^{1}$, Taeyoung Khim ${ }^{1}$, Sora Bak ${ }^{1}$, Jangkun Song ${ }^{3}$ \& \\ Byoungdeog $\mathrm{Choi}^{3 \mathrm{~W}}$
}

In this paper, we investigate the $\mathrm{V}_{\text {th }}$ shift of $\mathrm{p}$-type LTPS TFTs fabricated on a polyimide (PI) and glass substrate considering charging phenomena. The $V_{t h}$ of the LTPS TFTs with a PI substrate positively shift after a bias temperature stress test. However, the $V_{t h}$ with a glass substrate rarely changed even with increasing stress. Such a positive $V_{t h}$ shift results from the negative charging of fluorine stemmed from the PI under the gate bias. In fact, the $\mathrm{C}-\mathrm{V}$ characterization on the metal-insulator-metal capacitor reveals that charging at the $\mathrm{SiO}_{2} / \mathrm{PI}$ interface depends on the applied gate bias and the $\mathrm{PI}$ material, which agrees well with the TCAD simulation and SIMS analyses. As a result, the charging at the $\mathrm{SiO}_{2} / \mathrm{Pl}$ interface contributes to the $\mathrm{V}_{\text {th }}$ shift of the LTPS TFTs leading to image sticking.

Recently, flexible displays have attracted considerable attention as next-generation drivers in display industries ${ }^{1,2}$. Because low-temperature polycrystalline silicon (LTPS) thin-film transistors (TFT) have the advantages of low temperature process integration and high mobility, they have rapidly become popular in flexible displays and applications. However, the usage of excimer laser annealing (ELA) for the crystallization of amorphous silicon (a-Si) and chemical vapor deposition (CVD) for the process of gate insulation produce hysteresis loops in the device characterization, due mainly to the material and physical constraints of defects and non-uniformity ${ }^{3,4}$. In turn, such intrinsic limitations impact fluctuations of electric current that flows into the organic light emitting diodes (OLED), leading to TFT instability and display performance disturbance, including halo and image sticking ${ }^{5,6}$. In addition, moisture and oxygen penetration are serious deficiencies of all plastic substrates available for OLED flexible display applications ${ }^{7,8}$. In particular, OLED's lifetime decreases when exposed to oxygen and moisture. When fabricating a device on a flexible plastic substate, an inorganic layer (barrier) such as $\mathrm{SiO}_{2}, \mathrm{SiN}_{\mathrm{x}}$, or $\mathrm{Al}_{2} \mathrm{O}_{3}$ is deposited on the plastic substrate to prevent moisture and oxygen from penetrating into the OLED 9 . Although the main causes of residual images on OLED displays are inherently related to the process variation of the backplane process and deterioration of the OLED material ${ }^{10,11}$, TFT instability can aggravate image sticking under low frequencies and always-on-display applications ${ }^{12}$. A few papers are available for the elucidation of the mechanism and reliability physics of the positive $\mathrm{V}_{\text {th }}$ shift of $\mathrm{p}$-type LTPS TFT and image sticking in regards to the substrate material, process integrity, and bias stress test conditions ${ }^{13}$.

In this paper, information is given to elucidate the mechanism of the positive $V_{\text {th }}$ shift when the gate bias is applied to p-type LTPS TFTs fabricated on PI, as compared to a glass substrate. In order to probe the effects of charging on LTPS TFTs, three different metal-insulation-metal (MIM) capacitors were prepared for the C-V characterization. Finally, we delve into $V_{\text {th }}$ shift behaviors in the material properties of PI associated with the vertical structure of LTPS TFTs. The secondary ion mass spectrometry (SIMS) physical characterization and TCAD simulation are focused on the fluorine profile at the interface and effects of the polarity of charging on $\mathrm{V}_{\text {th }}$ shift behaviors.

\section{Results and Discussion}

$\mathrm{V}_{\text {th }}$ shift behaviors of LTPS TFTs fabricated on PI and glass substrates. Figure la shows the $\mathrm{I}_{\mathrm{D}}-\mathrm{V}_{\mathrm{G}}$ plot of p-type LTPS TFTs with glass and PI substrates on the top gate structure, before and after a gate stress of $-30 \mathrm{~V}$ for $4,000 \mathrm{~s}$ at $70^{\circ} \mathrm{C}$. In Fig. $1 \mathrm{~b}, \Delta \mathrm{V}_{\text {th }}$ after BTS was plotted as a box plot using 5 TFTs fabricated on the glass and PI substrate. On average, the $\Delta \mathrm{V}_{\mathrm{th}}$ of the TFT fabricated on glass showed a slight change, less than $-0.02 \mathrm{~V}$, and the $\Delta \mathrm{V}_{\text {th }}$ of the TFT fabricated on the PI showed a positive shift with an average $0.83 \mathrm{~V}$. In addition, $\mathrm{I}_{\mathrm{on}}$

${ }^{1}$ Samsung Display Co., Ltd, Technology Quality Reliability in OLED Business, Asan-si 31454, Korea. ${ }^{2}$ Department of Semiconductor and Display Engineering, Sungkyunkwan University, Suwon-si 16419, Korea. ${ }^{3}$ Department of Electrical and Computer Engineering, Sungkyunkwan University, Suwon-si 16419, Korea. ${ }^{\bowtie}$ email: bdchoi@ skku.edu 
(a)

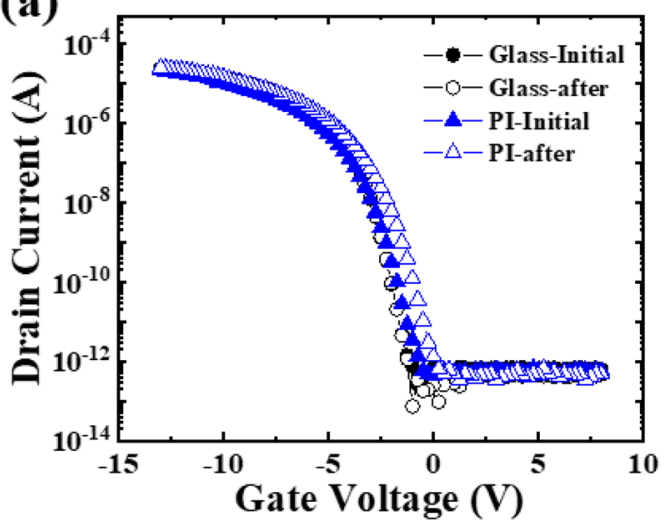

(b)

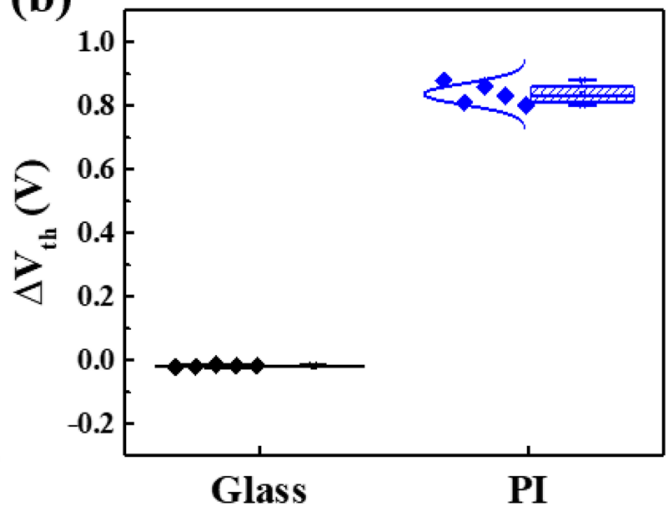

Figure 1. (a) $\mathrm{I}_{\mathrm{D}}-\mathrm{V}_{\mathrm{G}}$ plot of P-type LTPS TFTs before and after the BTS. Note that the P-type LTPS TFTs were fabricated on glass (black filled circle) and PI (blue filled triangle) substrates and (b) $\Delta \mathrm{V}_{\text {th }}$ before/after BTS of TFTs fabricated on glass and PI substrates.

(a)

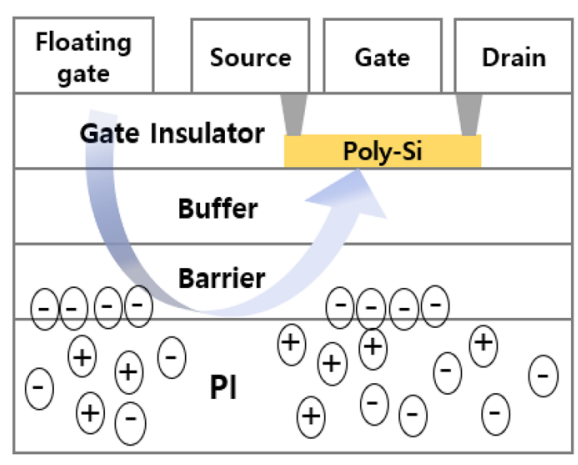

(b)

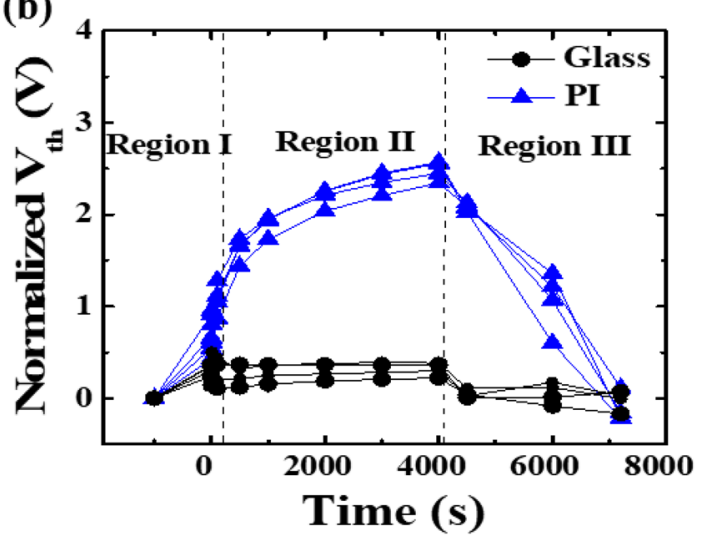

Figure 2. (a) Schematic of 4-pad characterization (floating gate, source, gate and drain) and (b) normalized $\mathrm{V}_{\text {th }}$ behaviors of P-type LTPS TFTs fabricated on the on glass (black filled circle) and PI (blue filled triangle) substrates.

increased from $2.08 \times 10^{-5}$ A to $2.46 \times 10^{-5} \mathrm{~A}$, and field effect mobility increased from 85 to $113 \mathrm{~cm}^{-2}$. However, under the identical stress conditions, the parameters of the LTPS TFT fabricated on glass substrate are rarely changed. It is somewhat interesting to note that the $V_{\text {th }}$ of p-type LTPS TFTs with a PI substrate is positively shifted under the negative gate bias. It is speculated that the negative charging is generated from the PI substrate below the gate insulation layer.

In order to further probe the positive $\mathrm{V}_{\text {th }}$ shifts, 4-pad evaluation was conducted. As shown in Fig. 2a, a bias of $50 \mathrm{~V}$ was applied to the floating gate adjacent to the LTPS TFT to minimize the effects of the poly channel on electrical charging in the PI substrate. $V_{\text {th }}$ behaviors are shown in Fig. $2 b$. As shown, the LTPS TFT with a glass substrate demonstrates stabilized $\mathrm{V}_{\text {th }}$ behaviors throughout stressing at $70{ }^{\circ} \mathrm{C}$ up to $80,000 \mathrm{~s}$. Note that Region I, II, and III represent the temperature and bias conditions used; $70^{\circ} \mathrm{C}$ without bias, $70{ }^{\circ} \mathrm{C}$ with $50 \mathrm{~V}$, and room temperature without bias, respectively. From Region I to II, the $\mathrm{V}_{\text {th }}$ of the TFT with a PI substrate increases and positively shifts with increasing time. The $V_{\text {th }}$ tends to decrease and then return to the initial $V_{\text {th }}$ after $1 \mathrm{~h}$ in Region III. In turn, Region III is intended to observe the recovery behaviors of the $V_{\text {th }}$ of the LTPS TFT with a PI substrate. Since the recovery of the $\mathrm{V}_{\mathrm{th}}$ observed in Region III could result in display image disturbance, such as image sticking defined as residual images, efforts in electrical and physical characterization are inevitable. One would argue that the positive $\mathrm{V}_{\text {th }}$ shifts of the TFT with a PI substrate mentioned are related to design flaws somehow associated with the layout design of the metal route, which can impact TFT stability as electrical fields arise from adjacent metals near TFT devices. However, such artifacts were eliminated by design review throughout circuit simulation.

Since the $V_{\text {th }}$ stability of TFT devices plays an important role for display image performance, particularly for image sticking, the relationship between the $\Delta \mathrm{V}_{\text {th }}$ vs. image sticking was investigated. Using the checkerboard test pattern, the image sticking index is estimated by comparing luminance changes before and after stressing ${ }^{13}$. The white area adjacent to black patterns in the checkerboard becomes darker after stressing, which indicates 


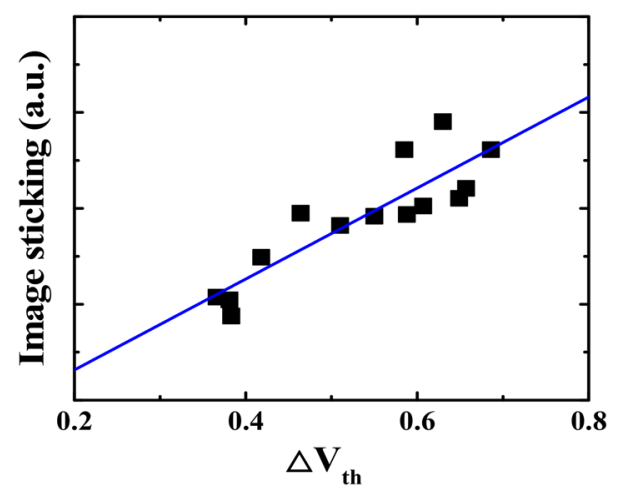

Figure 3. Correlation between PI charging induced $\mathrm{V}_{\text {th }}$ shift and image sticking for an LTPS TFT with a PI substrate.

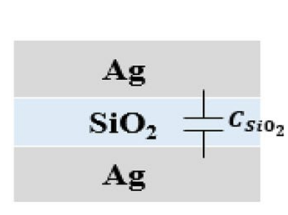

(a)

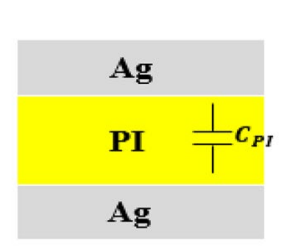

(b)

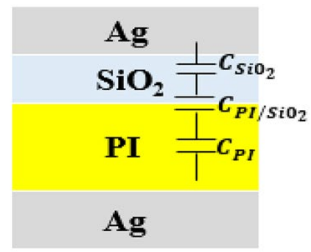

(c)

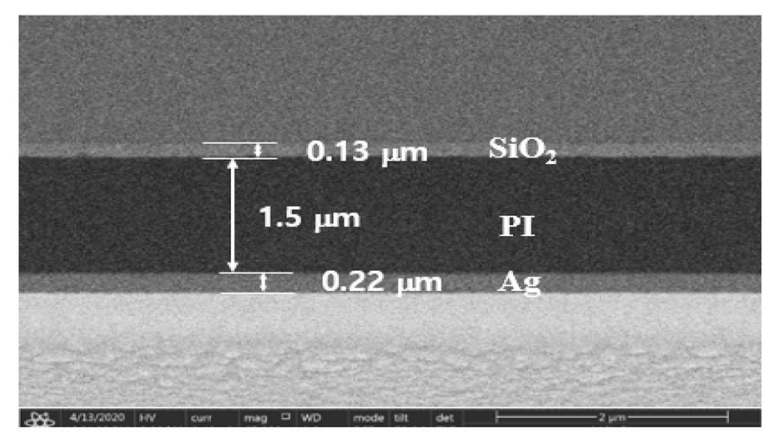

(d)

Figure 4. Schematics of the vertical structure for the MIM capacitors and SEM image; (a) $\mathrm{Ag} / \mathrm{SiO} / \mathrm{Ag},(\mathbf{b}) \mathrm{Ag} /$ $\mathrm{PI} / \mathrm{Ag},(\mathbf{c}) \mathrm{Ag} / \mathrm{SiO}_{2} / \mathrm{PI} / \mathrm{Ag}$ and (d) the cross-sectional analysis of the MIM capacitor shown in (c).

image sticking. Figure 3 shows the correlation between PI charging induced $\Delta \mathrm{V}_{\text {th }}$ and image sticking. It is shown that the larger the $\Delta \mathrm{V}_{\mathrm{th}}$, the higher the propensity for image sticking. These results show that the correlation between $\mathrm{V}_{\mathrm{th}}$ shift and image sticking needs to be further discussed with electrical and physical characterization.

MIM capacitor fabrication, C-V measurement and physical SIMS characterization. In an effort of probing the $\mathrm{V}_{\mathrm{th}}$ behaviors mentioned above, three different metal-insulator-metal (MIM) capacitors, such as $\mathrm{Ag} / \mathrm{PI} / \mathrm{Ag}, \mathrm{Ag} / \mathrm{SiO}_{2} / \mathrm{Ag}$ and $\mathrm{Ag} / \mathrm{SiO}_{2} / \mathrm{PI} / \mathrm{Ag}$ were prepared for the $\mathrm{C}-\mathrm{V}$ measurements conducted by varying voltage at a frequency of $100 \mathrm{kHz}$. $\mathrm{SIO}_{2}$ is the barrier layer of the LTPS TFT, and the thickness and process conditions are the same with the measured TFT. Figures $4 \mathrm{a}-\mathrm{d}$ show the schematics of the vertical structure for the MIM capacitors, i.e., $\mathrm{Ag} / \mathrm{SiO}_{2} / \mathrm{Ag}, \mathrm{Ag} / \mathrm{PI} / \mathrm{Ag}, \mathrm{Ag} / \mathrm{SiO}_{2} / \mathrm{PI} / \mathrm{Ag}$, and the cross-sectional analysis of the MIM capacitor. An Ag metal electrode was sputtered onto the spin-coated PI and $\mathrm{SiO}_{2}$, deposited using the PECVD process. As a result, the $\mathrm{PI}$ and $\mathrm{PI} / \mathrm{SiO}_{2}$ function as the insulators between the metal electrodes.

Using Eq. (1), the physical dimension, dielectric constant, and capacitance of each capacitor are estimated and summarized in Table 1.

$$
\frac{1}{\mathrm{C}_{\mathrm{Total}}}=\frac{1}{\mathrm{C}_{\mathrm{SiO}_{2}}}+\frac{1}{\mathrm{C}_{\mathrm{PI}}}+\frac{1}{\mathrm{C}_{\mathrm{PI} / \mathrm{SiO}_{2}}}
$$

Figure 5 shows the results obtained from the $\mathrm{C}-\mathrm{V}$ measurements. It is apparent that changes in capacitance depend on the MIM capacitors. The capacitances of the $\mathrm{SiO}_{2}$ and PI dielectric insulators between the $\mathrm{Ag}$ 


\begin{tabular}{|l|l|l|l|}
\hline & $\mathrm{SiO}_{2}$ & $\mathbf{P I}$ & $\mathbf{P I} / \mathrm{SiO}_{2}$ \\
\hline Thickness (um) & 0.13 & 1.5 & - \\
\hline Dielectric constant & 3.8 & 3.91 & - \\
\hline Capacitance $(\mathrm{F})$ & $6.37 \times 10^{-9}$ & $7.56 \times 10^{-10}$ & $9.39 \times 10^{-11}$ \\
\hline$\Delta \mathrm{Q} / \mathrm{q}$ for $30 \mathrm{~V}$ stress $\left(/ \mathrm{cm}^{2}\right)$ & $2.7 \times 10^{10}$ & $5.3 \times 10^{10}$ & $2.0 \times 10^{11}$ \\
\hline
\end{tabular}

Table 1. MIM capacitance and parameters from $\mathrm{C}-\mathrm{V}$ measurement.
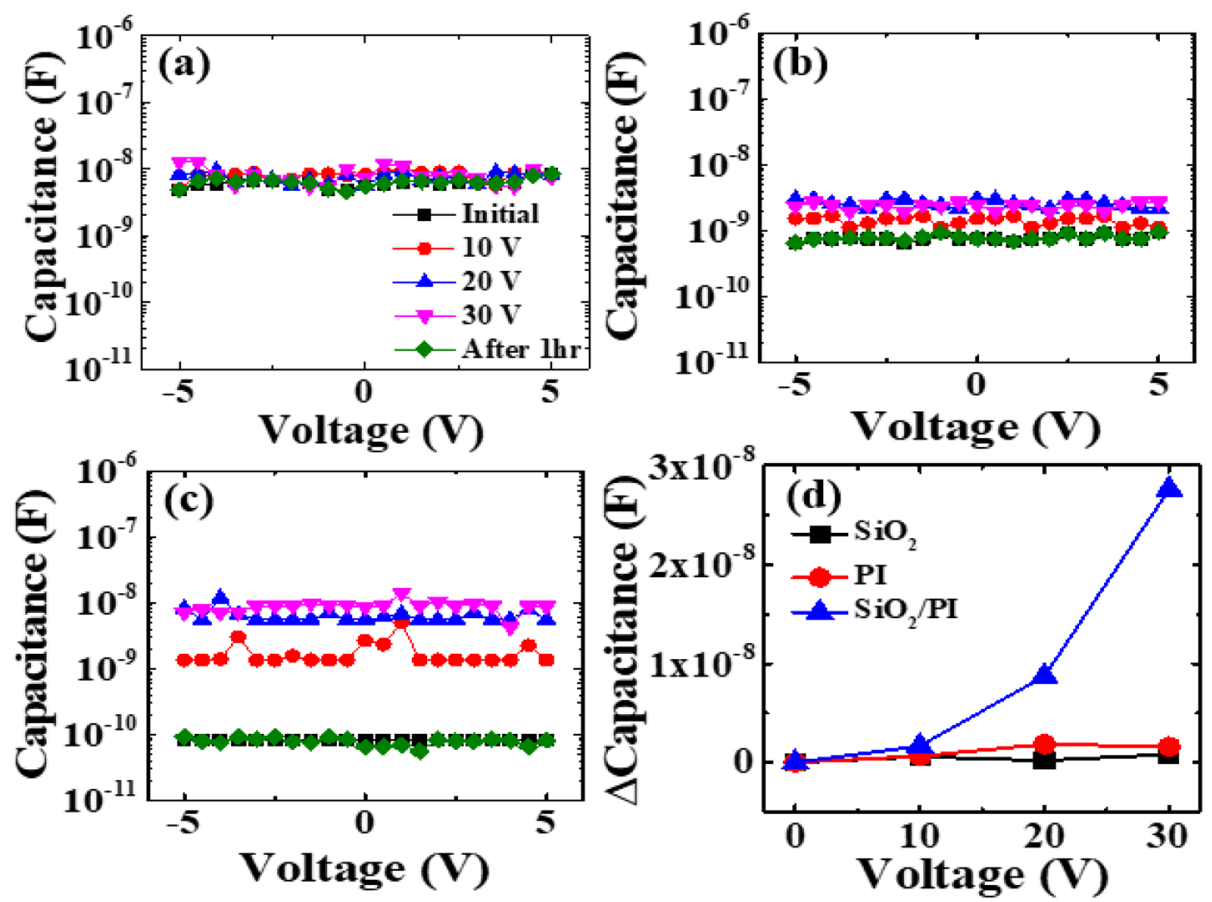

Figure 5. $\mathrm{C}-\mathrm{V}$ characterization for 3 different $\mathrm{MIM}$ capacitors with increasing voltage; (a) $\mathrm{Ag} / \mathrm{SiO} / 2 / \mathrm{Ag},(\mathbf{b}) \mathrm{Ag} /$ $\mathrm{PI} / \mathrm{Ag}$, (c) $\mathrm{Ag} / \mathrm{SiO}_{2} / \mathrm{PI} / \mathrm{Ag}$, and (d) the dependency of the MIM capacitors on the applied voltage.

electrodes rarely change, even with increasing voltage (see Fig. 5a,b). However, the capacitance of the $\mathrm{SiO}_{2} / \mathrm{PI}$ dielectric tends to increase with increasing voltage. It was also found that the magnitude of capacitance turns into the initial state after $1 \mathrm{~h}$ of halting bias, as shown in Fig. 5c. In Fig. 5d, the capacitance of the $\mathrm{SiO}_{2} / \mathrm{PI}$ rapidly increases with increasing voltage. Such results agree well with the recovery of the $\mathrm{V}_{\text {th }}$ described in Fig. 2b. Thus, it is legitimate that the positive $\mathrm{V}_{\text {th }}$ shift of a TFT with a PI substrate is attributed to charging between the $\mathrm{SiO}_{2}$ and $\mathrm{PI}$ interface. As such, charge generation at the interface between the $\mathrm{SiO}_{2}$ and the PI plays an important role for TFT device stability, particularly for the PI substrate.

In sequence, SIMS analysis is adopted to explicate the positive $\mathrm{V}_{\text {th }}$ shifts of p-type LTPS TFTs with a PI substrate. To understand the effects of PI on the $\mathrm{V}_{\mathrm{th}}$ shift, two different PIs with low and high crosslink density, named $\mathrm{PI}-\mathrm{A}$ and $\mathrm{PI}-\mathrm{B}$, were chosen to prepare the $\mathrm{Ag} / \mathrm{SiO}_{2} / \mathrm{PI} / \mathrm{Ag}$ capacitor. We first suspected that oxygen or moisture had penetrated from the PI. Changes in hydrogen ions $\left(\mathrm{H}^{-}\right)$, hydroxyl group $\left(\mathrm{OH}^{-}\right)$, and oxygen ions $\left(\mathrm{O}^{-}\right)$before/ after bias stress of $\mathrm{Ag} / \mathrm{SiO}_{2} / \mathrm{PI} / \mathrm{Ag}$ capacitors were confirmed through SIMS analysis. Figure 6 shows the results of SIMS analysis before and after bias stress of MIM capacitors fabricated based on PI-A and PI-B. There was no change in $\mathrm{H}^{-}, \mathrm{OH}^{-}$, or $\mathrm{O}^{-}$before/after bias stress, confirming that there was no penetration of oxygen or moisture from PIs. Figure 7 shows the correlation between the fluorine profile at the $\mathrm{SiO}_{2} / \mathrm{PI}$ interface and capacitance, characterized by SIMS and C-V measurement. Comparatively, the SIMS analyses revealed that PI-A has a higher florin content than PI-B at the interface (see Fig. 7a,c). In consequence, C-V measurements shown in Fig. 7b,d show that the capacitance of the MIM capacitor with PI-B is rarely changed even with increased stressing at $70{ }^{\circ} \mathrm{C}$. It has been reported that the negative fluorine ions, $\mathrm{F}^{-}$, are subjected to transfer and trapped in $\mathrm{the} \mathrm{SiO}_{2}$ under the bias ${ }^{14}$. As a result, SIMS analyses evidences that a mobile ion $\mathrm{F}^{-}$in the $\mathrm{SiO}_{2} / \mathrm{PI}$ interface contributes to the positive shifts of LTPS TFTs with a PI substrate. This suggests that the amount of charging generated in the $\mathrm{PI}$ is dependent on the material property of the PI. Hence, the material property of the PI is a crucial factor that can influence LTPS TFTs with a PI substrate. It has been also found that PI charging that significantly affects TFT reliability can be successfully suppressed by the selection of a proper PI with high volume resistivity ${ }^{15}$. However, the charge generation and transfer into the barrier layer remained in unripe areas. 

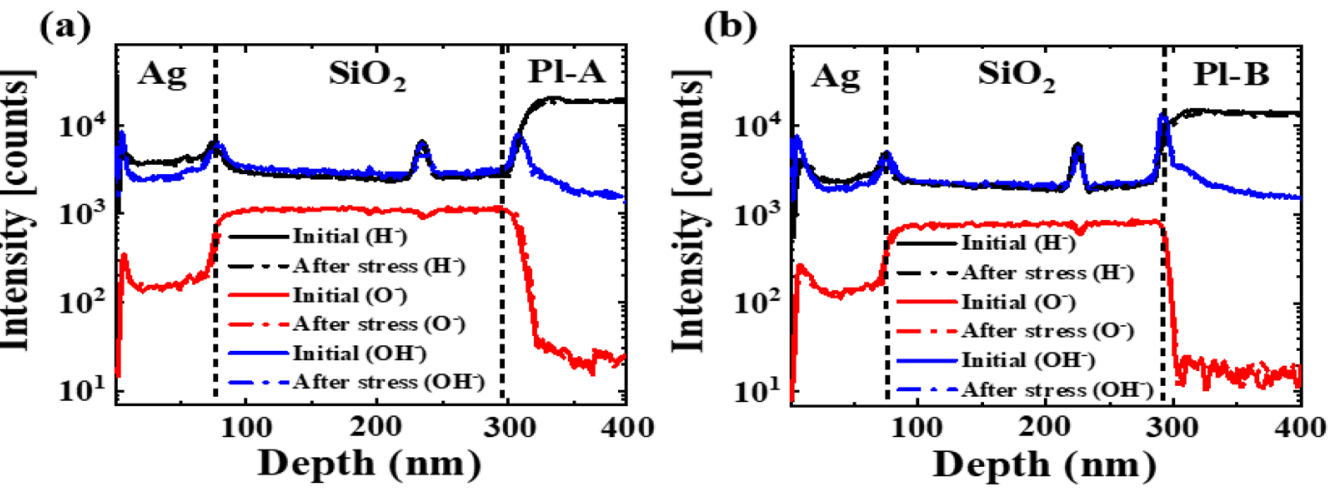

Figure 6. Hydrogen, hydroxy group and oxygen profiles obtained by SIMS measurements of capacitors before/ after bias stress; (a) $\mathrm{Ag} / \mathrm{SiO}_{2} / \mathrm{PI}-\mathrm{A} / \mathrm{Ag}$ and (b) $\mathrm{Ag} / \mathrm{SiO}_{2} / \mathrm{PI}-\mathrm{B} / \mathrm{Ag}$.
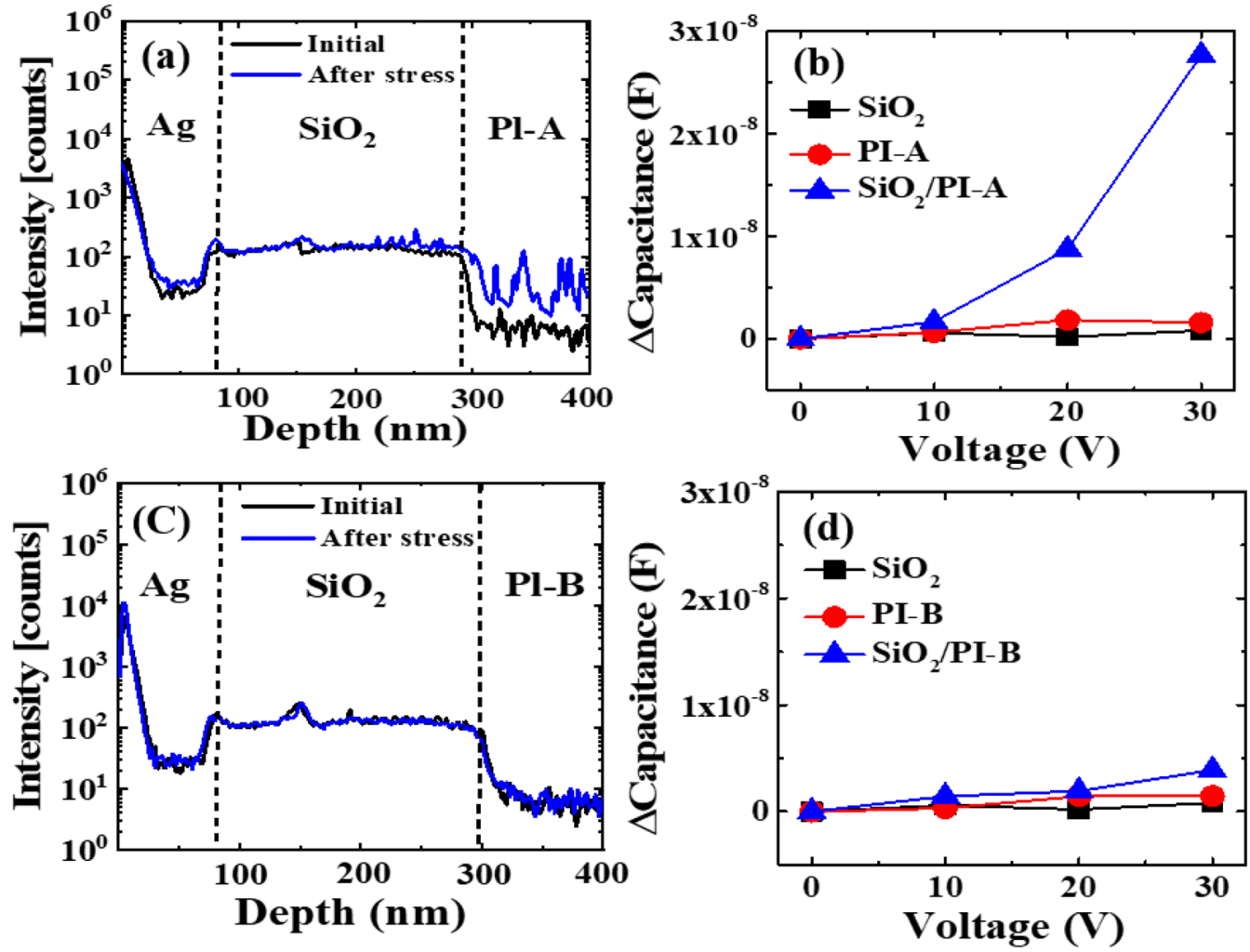

Figure 7. SIMS characterization of $\mathrm{Ag} / \mathrm{SiO}_{2} / \mathrm{PI} / \mathrm{Ag}$ capacitor focused on fluorine profile at the interface; $(\mathbf{a}, \mathbf{b})$ with PI-A type and (c, d) with PI-B type. Note that PI-A is less crosslink density than PI-B.

TCAD simulation for charge generation at the interface between the $\mathrm{SiO}_{2}$ and $\mathrm{PI}$. Based on empirical data collected from reliability assessments, Silvaco TCAD was used to simulate the effects of charging at the $\mathrm{SiO}_{2} / \mathrm{PI}$ interface on the TFT transfer curve. Figure 8 shows the $\mathrm{I}_{\mathrm{D}}-\mathrm{V}_{\mathrm{G}}$ plot of an LTPS TFT with a PI substrate. As shown, the negative charging in the $\mathrm{SiO}_{2} / \mathrm{PI}$ interface shifts the $\mathrm{V}_{\mathrm{th}}$ to the positive direction, while the positive charging results in a negative $V_{\text {th }}$ shift. Accordingly, when $-2 \times 10^{11} / \mathrm{cm}^{2}$ charging is generated at the interface between the $\mathrm{SiO}_{2}$ and the $\mathrm{PI}$, the estimated $\mathrm{V}_{\text {th }}$ shift toward the positive direction is $0.84 \mathrm{~V}$.

Table 2 contains the estimated TFT parameters, such as $\mathrm{V}_{\mathrm{th}}, \mu_{\mathrm{FE}}$, subthreshold swing (SS), and on/off ratio, based on the given charge injections shown in Fig. 8.

Figure 9 is given to explain the hole concentration of an LTPS TFT with a PI substrate with the bias conditioned at $\mathrm{V}_{\mathrm{GS}}-30 \mathrm{~V}$ and $\mathrm{V}_{\mathrm{DS}}-0.1 \mathrm{~V}$. The Reference (black filled circle) and $-2 \times 10^{11} / \mathrm{cm}^{2}$ (blue filled triangle) represent the LTPS TFT with and without charging at the $\mathrm{SiO}_{2}$ and PI interface. Recall that $2 \times 10^{11} / \mathrm{cm}^{2}$ is obtained from the C-measurement summarized in Table 1. As shown in the inlet in Fig. 9, when the negative bias is applied to the gate of the LTPS TFT, hole carriers tend to be accumulated near the channel and then 


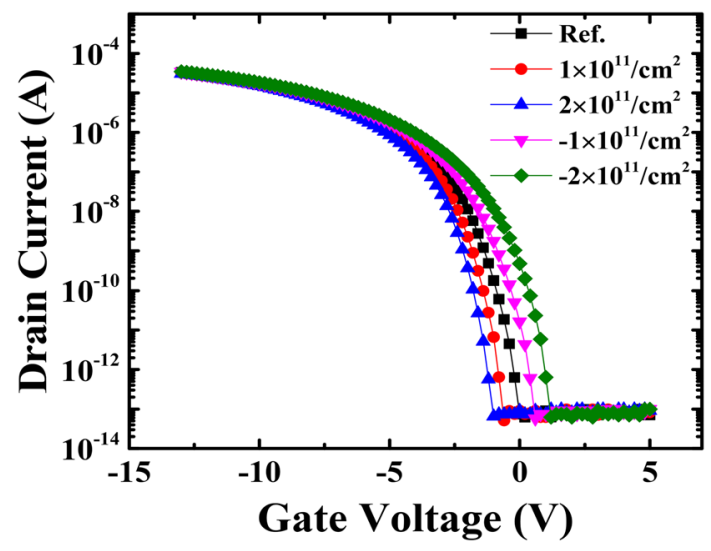

Figure 8. $\mathrm{I}_{\mathrm{D}}-\mathrm{V}_{\mathrm{G}}$ plot based on the amount of charge trapped at the $\mathrm{SiO}_{2}$ and PI interface by TCAD simulation.

\begin{tabular}{|l|l|l|l|l|}
\hline Charge Injection $\left(/ \mathbf{c m}^{2}\right)$ & $\mathbf{V}_{\text {th }}(\mathbf{V})$ & $\boldsymbol{\mu}_{\mathrm{FE}}\left(\mathbf{c m}^{2} / \mathrm{V}-\mathbf{s}\right)$ & $\mathbf{S S}(\mathrm{V} / \mathbf{d e c})$ & On/off ratio \\
\hline Ref & -1.47 & 82 & 0.43 & $4.21 \times 10^{8}$ \\
\hline $1 \times 10^{11}$ & -1.92 & 75 & 0.40 & $3.93 \times 10^{8}$ \\
\hline $2 \times 10^{11}$ & -2.27 & 69 & 0.33 & $3.79 \times 10^{8}$ \\
\hline$-1 \times 10^{11}$ & -1.02 & 90 & 0.45 & $4.57 \times 10^{8}$ \\
\hline$-2 \times 10^{11}$ & -0.63 & 101 & 0.46 & $5.58 \times 10^{8}$ \\
\hline
\end{tabular}

Table 2. Estimated TFT parameters with respect to charge injection from the $\mathrm{SiO}_{2} / \mathrm{PI}$ interface by TCAD simulation.

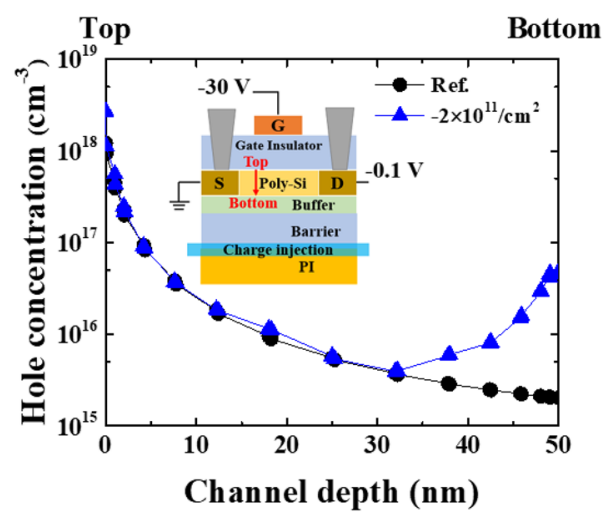

Figure 9. TCAD simulation for hole concentration $\left(\mathrm{cm}^{-3}\right)$ versus channel depth $(\mathrm{nm})$ of an LTPS TFT with a PI substrate. Reference represents a LTPS TFT with a PI substrate without charge injection at the $\mathrm{SiO}_{2} / \mathrm{PI}$ interface.

exponentially decrease. However, when negative charging exists at the PI substrate, hole concentration decreases then increases below the channel depth of $30 \mathrm{~nm}$. It is known that the negative charges at the interface between the $\mathrm{SiO}_{2}$ and PI result in an early turn-on $\mathrm{V}_{\text {th }}$ leading to increased field effective mobility and $\mathrm{I}_{\text {on }}$, which is similar to the $I_{D}-V_{G}$ characteristic observed from the double gate TFTs ${ }^{16,17}$. Hence, the state of charging at the interface determines the characteristics of the LTPS TFTs with a PI substrate.

\section{Conclusions}

Considering the direction of $\mathrm{V}_{\text {th }}$ shift of $\mathrm{p}$-type LTPS TFTs with gate bias stress, the charge trapping mechanism, depending on the type of the substrate in the top gate structure, are comprehensively investigated. Unlike the glass substrate, the positive $\mathrm{V}_{\text {th }}$ shift of p-type LTPS TFTs with a PI substrate under the BTS test results from the negative charging of fluorine at the interface between the $\mathrm{SIO}_{2}$ and $\mathrm{PI}$ is proven by $\mathrm{C}-\mathrm{V}$ measurement and SIMS characterization. In fact, the fluorine stems from the PI substrate under gate bias stress. Furthermore, TCAD simulation reveals that the direction of the $\mathrm{V}_{\mathrm{th}}$ shift strongly depends on the polarity of charge trapping at the $\mathrm{SiO}_{2}$ and PI interface. The larger $\mathrm{V}_{\text {th }}$ shifts are prone to the higher propensity of image sticking. Hence, 
care must be taken for the selection of PI in order to ensure display image performance in advanced flexible display technologies.

\section{Methods}

P-type LTPS TFTs were fabricated on either a PI or glass substrate through the standard backplane process, in which plasma enhanced chemical vapor deposition (PECVD) was used for a-Si and $\mathrm{SiO}_{2}$ (barrier) deposition and crystallized into poly-Si by using excimer laser annealing (ELA). Thus, the vertical structure of the p-type LTPS TFTs consists of the gate/gate insulator/poly-Si/buffer/barrier/PI or glass substrate on the top gate structure. In a pixel circuit driver, $4 / 4 \mu \mathrm{m}$ transistor and $200 \mu \mathrm{m} / 200 \mu \mathrm{m}$ capacitance were monitored by $\mathrm{I}-\mathrm{V}$ and $\mathrm{C}-\mathrm{V}$ measurement. $\mathrm{V}_{\text {th }}$ behaviors were monitored as a function of bias stress on the gates of the LTPS TFTs. To probe electrical charging in PI, three different metal-insulator-metal (MIM) capacitors, $\mathrm{Ag} / \mathrm{PI} / \mathrm{Ag}, \mathrm{Ag} / \mathrm{SiO}_{2} / \mathrm{Ag}$, and $\mathrm{Ag} / \mathrm{SiO}_{2} / \mathrm{PI} / \mathrm{Ag}$, were prepared for the $\mathrm{C}-\mathrm{V}$ measurements. Changes in capacitance were measured as a function of voltage level. Moreover, the effects of charging in PI on the LTPS TFTs were taken into accounted by selecting different types of PIs such as PI-A and PI-B. Fluorine profiles were carefully analyzed by SIMS characterization. Finally, the effects of PI charging on the LTPS TFTs were consummated by using TCAD simulation.

Received: 20 July 2020; Accepted: 6 April 2021

Published online: 16 April 2021

\section{References}

1. Kim, H. J. et al. The effects of valence band offset on threshold voltage shift in a-InGaZnO TFTs under negative bias illumination stress. IEEE Electron Dev. Lett. 41, 737-740 (2020).

2. Meng, Z., Wang, M. \& Wong, M. High performance low temperature metal-induced unilaterally crystallized polycrystalline silicon thin film transistors for system-on-panel applications. IEEE Trans. Electron Dev. 47, 404-409 (2000).

3. Lin, C. W., Cheng, L. J., Lu, Y. L., Lee, Y. S. \& Cheng, H. C. High performance low-temperature poly-Si TFTs crystallized by excimer laser irradiation with recessed-channel structure. IEEE Electron Dev. Lett. 22, 269-271 (2001).

4. Jin, D. et al. World-largest (6.5”) flexible full color top emission AMOLED display on plastic film and its bending properties. SID Symp. Tech. Dig. Pap. 09, 983-985 (2009).

5. Jin, G. H. \& Kim, M. J. Characteristics of excimer laser-annealed thin-film transistors on the polycrystalline silicon morphology formed in the single and double (overlap) scanned area. Jpn. J. Appl. Phys. 49, 041301-041306 (2010).

6. Yamaguchi, K. Modeling and characterization of polycrystalline-silicon thin-film transistors with a channel-length comparable to a grain size. J. Appl. Phys. 89, 590-595 (2001).

7. Greener, J., Ng, K. C., Vaeth, K. M. \& Smith, T. M. Moisture permeability through multilayered barrier films as applied to flexible OLED display. J. Appl. Polym. Sci. 106, 3534-3542 (2007).

8. Chwang, A. B. et al. Thin film encapsulated flexible organic electroluminescent displays. Appl. Phys. Lett. 83, 413-415 (2003).

9. Chen, J. \& Liu, C. T. Technology advances in flexible displays and substrates. IEEE Access. 1, 150-158 (2013).

10. Kim, H. J., Lee, J. W., Bang, J. H., Lee, B. R., Hwang, Y. S. \& Park, J. W. Fast cell level characterization and reliability evaluation for advanced flexible mobile display. 2017 IEEE International Reliability Physics Symposium (IRPS) Conference (pp. 6C-6.1-6C-6.6). https://doi.org/10.1109/IRPS.2017.7936349 (2017).

11. Lee, J. W., Kim, S. G., Choi, Y. S. \& Park, J. W. Process variation of pixel definition and effects of flexible OLED luminance degradation. 2019 IEEE International Reliability Physics Symposium (IRPS) Conference (pp. 1-6). https://doi.org/10.1109/IRPS.2019.87205 29 (2019).

12. Kim, B. K., Kim, O. Y., Chung, H. J., Chang, J. W. \& Ha, Y. M. Recoverable residual image induced by hysteresis of thin film transistors in active matrix organic light emitting diode displays. Jpn. J. Appl. Phys. 43, 482-485 (2004).

13. Kim, J. H. et al. Vt behaviors of LTPS-TFT fabricated on PI substrate for flexible applications. SID Symp. Tech. Dig. Papers. 48, $1773-1776$ (2017).

14. Williams, R. \& Woods, M. H. Mobile fluoride ions in $\mathrm{SiO}_{2}$. J. Appl. Phys. 46, 695-698 (1975).

15. Kinoshita, T. et al. Requirement of a polyimide substrate to achieve high thin-film-transistor reliability. SID Symp. Tech. Dig. Papers. 49, 888-891 (2018).

16. Tasi, C. C. et al. High-performance short-channel double-gate low-temperature polysilicon thin-film transistors using excimer laser crystallization. Electron Dev. Lett. 28, 1010-1013 (2007).

17. Ikeno, R. \& Aoki, M. An equivalent electric-filed approximation for formulating sheet density of induced electrons in a silicon layer of symmetric and asymmetric double-gate SOI MOSFETs. Solid State Electron 44, 606-611 (2000).

\section{Acknowledgements}

This work was supported by the Industrial Human Resources and Skill Development Program (P0012453, Nextgeneration Display Expert Training Display Expert Training Project for Innovation Process and Equipment, Materials Engineers) funded by the Ministry of Trade, Industry, and Energy (MOTIE, Korea). And we thank Yun Jung Jang from Korea Institute of Science and Technology (KIST) for helping us perform the ToF-SIMS experiments.

\section{Author contributions}

H.K., J.P., T.K., J.S. and B.C. designed this work. H.K. and S.B. fabricated the devices, and H.K., J.P., T.K., S.B., J.S. and B.C. measured the electrical characteristics of the devices and performed analysis. H.K performed SEM analysis of the MIM capacitor in Fig. 4d. H.K. and J.P. conducted the TCAD simulation. Figures 8 and 9 are plots extracted through TCAD simulation. All authors discussed the findings and contributed to writing the manuscript.

\section{Competing interests}

The authors declare no competing interests.

\section{Additional information}

Correspondence and requests for materials should be addressed to B.C. 
Reprints and permissions information is available at www.nature.com/reprints.

Publisher's note Springer Nature remains neutral with regard to jurisdictional claims in published maps and institutional affiliations.

(c) (i) Open Access This article is licensed under a Creative Commons Attribution 4.0 International License, which permits use, sharing, adaptation, distribution and reproduction in any medium or format, as long as you give appropriate credit to the original author(s) and the source, provide a link to the Creative Commons licence, and indicate if changes were made. The images or other third party material in this article are included in the article's Creative Commons licence, unless indicated otherwise in a credit line to the material. If material is not included in the article's Creative Commons licence and your intended use is not permitted by statutory regulation or exceeds the permitted use, you will need to obtain permission directly from the copyright holder. To view a copy of this licence, visit http://creativecommons.org/licenses/by/4.0/.

(C) The Author(s) 2021 